\title{
Study of the longitudinal expansion velocity of the substorm current wedge
}

\author{
A. Belehaki ${ }^{1}$, I. Tsagouri ${ }^{1,2}$ and H. Mavromichalaki ${ }^{2}$ \\ ${ }^{1}$ National Observatory of Athens, Institute of Ionospheric and Space Research, Metaxa and Vas. Pavlou str., Palaia Penteli 152 36, Greece \\ ${ }^{2}$ Nuclear and Particle Physics Section, Physics Department, University of Athens, Solonos 104, 10680 Athens, Greece
}

Received: 13 November 1997 / Revised: 27 February 1998 / Accepted: 25 March 1998

\begin{abstract}
In this work we examine simultaneous observations from the two geosynchronous satellites GOES-5 and GOES- 6 located at $282^{\circ} \mathrm{E}$ and $265^{\circ} \mathrm{E}$ respectively, and from middle and low latitude ground observatories located within $250^{\circ} \mathrm{E}$ and $294^{\circ} \mathrm{E}$ geographic longitude, during isolated substorms of moderate activity. The spatial distribution of our observation points allows us to make a detailed study of the azimuthal expansion of the substorm current wedge. The data analysis shows evidence that the substorm initiation and development mechanism include the cross-tail current diversion/ disruption, the substorm current wedge formation and the azimuthal expansion of the inner plasma sheet. The triggering mechanism is initially confined in a longitudinally narrow sector, estimated to be less than $15^{\circ}$ and located very close to local midnight to the east or to the west. The current disruption region expands both eastward and westward in the magnetotail, so that the location of major field-aligned currents flowing into the ionosphere shifts successively eastward, and the location of the currents flowing out of the ionosphere shifts successively westward. Evidence was found that the perturbation travels toward the west with velocities greater than those expanding the wedge eastward. The drastic decrease of the velocity with the azimuthal distance from the location of the disturbance initiation, i.e., the onset sector, indicates that the energy release is a very localized phenomenon. Finally, the transient D perturbation observed by the geosynchronous satellites suggests that the field-aligned currents forming the wedge have a longitudunally limited extent.
\end{abstract}

Key words. Magnetospheric physics (current systems; magnetosphere-ionosphere interactions)

\section{Introduction}

Quiet time magnetospheric models suggest that the magnetic field configuration near the geostationary orbit $(6.6 \mathrm{Re})$ should be nearly that of a dipole. However, during periods of enhanced geomagnetic activity the configuration is distorted from the dipolar topology. Studies of the geosynchronous region have indicated that a tail-like magnetic field configuration can develop near by just prior to substorm onsets (Cummings et al., 1968; Maynard et al., 1996; Nagai, 1982) and efforts have been made to reproduce this field configurational change (Kaufmann, 1987; Tsyganenko, 1989, 1997). During substorm expansion, a relaxation of the tail-like field geometry to a more dipolar state is often observed by geosynchronous spacecraft (e.g. Sauvaud and Winckler, 1980). This process is called dipolarization and it is believed to result from a partial disruption and diversion of the cross-tail current into the ionosphere to form the substorm current wedge SCW (McPherron et al., 1973; Lui, 1978; Kaufmann, 1987). A significant fraction of the cross-tail current in the near-tail is diverted via field-aligned currents (FACs) down into the eastern side of the midnight sector of the auroral oval at substorm onset, where it adds to the westward electrojet and then returns to the tail via outward FACs on the western side. Within the SCW the magnetic field relaxes toward a more dipolar configuration marked primarily by an enhanced northward magnetic field component (Slavin et al., 1997). Above the plane of the current sheet, this behavior is primarily manifested by an increase in $B x$ and $|B|$ (often accompanied by a decrease in $B z$ ), while in the plane of the current sheet, $B z$ and $|B|$ decrease (Lopez et al. 1988a).

The current wedge initially develops within a restricted time sector near local midnight. Previous studies have revealed that the SCW is not stationary with time. Since the auroral substorm activity expands in both latitude 
and local time, this is mapped in the magnetotail as widening of the current disruption region in radial extent and in local time as substorm progress (Akasofu, 1972). The study of the magnetic field data provided by the geosynchronous satellites GOES-2 and GOES-3 has revealed a longitudinal expansion with time both eastward and westward (Nagai, 1982). Magnetic field and energetic particle data from two geostationary satellites GOES-5 and GOES- 6 relative to the AMPTE/CCE (at 8 $\mathrm{Re}$ ) and AMPTE/IRM (at 11.6 Re) satellite data during a substorm that occurred on April 19, 1985, at 0830 UT, provided significant evidence that the region of substorm initiation is also radially limited (Lopez and Lui, 1990). The disruption of the cross-tail current sheet, the formation of the SCW and the expansion of the plasma sheet begin in the near-Earth region and subsequently spread tailward as well as longitudinally (Lopez and Lui, 1990; Lopez et al., 1990; Ohtani et al., 1991). Therefore the time when a particular satellite observes a dipolarization of the magnetic field is defined to be the local substorm onset (Lopez et al., 1989). Releases of magnetotail energy can be realized through the development of the substorm current wedge (Rostoker et al., 1987). Each activation of the substorm current wedge signals the onset of a substorm intensification (Baumjohann, 1983). The cross-tail current diversion and/ or disruption which lead to the substorm current wedge formation (McPherron et al., 1973) is a localized process that is followed by the release of a large amount of energy over a wide region.

From this description of the research progress done on this subject, it is evident that the manner in which the SCW initially forms and spreads longitudinally (Kokubun and McPherron, 1981) and radially down the tail (Jacquey et al., 1991) is still the subject of active research and conflicting theoretical models (Hesse and Birn, 1991; Lui, 1996; Rostoker, 1996). The purpose of this contribution is to determine the time sequence of the events that make up a magnetospheric substorm phenomenon at geosynchronous orbit $(6.6 \mathrm{Re}$ radial distance), and to estimate the velocity of the eastward and westward expansion of the substorm current wedge. For this purpose we have selected isolated substorms during which GOES-5 and GOES-6 were located in magnetic local time between 2200 and 0200 .

\section{Substorm current wedge signature identification from geosynchronous satellites and ground data}

For visualizing substorm dynamics in the inner magnetosphere it is useful to consider the magnetic field measured from geosynchronous satellites in VDH coordinates. The $\mathrm{V}$ component points radially outward in a plane parallel to the magnetic equatorial plane, $\mathrm{H}$ is aligned with the Earth's magnetic dipole axis, and D completes the right-handed system, positive toward the east. During the substorm growth phase the signatures of the tail-like configuration appear as an enhancement in the absolute value of $\mathrm{V}$-component and a depression in H-component. The effect of disrupting the cross-tail currents, which marks the substorm onset, is to dipolarize the inner magnetosphere. At the time of substorm onset the $\mathrm{H}$ component increases rapidly whereas the magnitude of the absolute value of $\mathrm{V}$ component decreases. Variations observed in the D component provide information about field-aligned currents (FACs). Nagai (1982) found activations in D at geosynchronous altitude, commencing at the time of ground onset and peaking at the start of dipolarization. They interpret D variations as resulting from the diversion of the cross-tail current to the FACs connected to the westward electrojet. Also, sharp decreases in $\mathrm{H}$ occurred just prior to dipolarization and simultaneous with the peak in the $\mathrm{D}$ component.

It is of significant importance to consider the satellite position with respect to the disturbed current system. According to Ohtani et al. (1992) if the spacecraft is located far from the onset region, it will observe the gradual changes in the magnetic field disturbance due to the time accumulation of the effects of the current disruption, which is expanding in both the radial or azimuthal directions. On the other hand, if the spacecraft is located close to the onset sector, most of the contribution to the reconfiguration will come from the current disruption near the spacecraft, and therefore the spacecraft should observe a sharp change in the field configuration seen in the $\mathrm{H}$-component. In contrast to sharp $\mathrm{H}$ recoveries, sharp $\mathrm{V}$ recoveries can be caused by the rapid movement of the spacecraft relative to the current layer, and therefore does not necessarily mean the occurrence of onsets close to spacecraft.

For the purpose of this work, we analyzed magnetic field data during selected substorm events, from the two geostationary satellites GOES-5 and GOES-6. Information on the positions of GOES-5 and GOES- 6 is given in Table 1. GOES-6 was located at a local time meridian approximately $2 \mathrm{~h}$ westward of GOES-5. The satellite distances from the magnetic equator plane are $\sim 1.3 \mathrm{Re}$ (north) for GOES-5 and $\sim 1$ Re (north) for GOES-6. The neutral sheet deviation from the magnetic equator plane is negligible according to the expression established by Lopez (1990), so these values also correspond to the satellites' position with respect to the neutral sheet. GOES data are represented originally in the righthanded orthogonal HP, HE, HN coordinates. To calculate the disturbance values of the field due to current's intensification and/or disruption, quiet-time magnetic field values have been subtracted from the GOES magnetic field values. To estimate the quiet values we have selected intervals occurring at approximately the same local time with the disturbance, during an interval of 10 days before and 10 days after the substorm, during which AE index did not exceed the

Table 1. Location of synchronous satellites

\begin{tabular}{llll}
\hline Satellite & $\begin{array}{l}\text { Geographic } \\
\text { longitude, }{ }^{\circ} \mathrm{E}\end{array}$ & $\begin{array}{l}\text { Geomagnetic } \\
\text { longitude, }{ }^{\circ} \mathrm{E}\end{array}$ & $\begin{array}{l}\text { Geomagnetic } \\
\text { latitude, }{ }^{\circ} \mathrm{N}\end{array}$ \\
\hline GOES-5 & 285.0 & 356.0 & 11 \\
GOES-6 & 252.0 & 322.5 & 9 \\
\hline
\end{tabular}


Table 2. The coordinates of the magnetic observatories referred to in this study

\begin{tabular}{|c|c|c|c|c|c|}
\hline \multirow[t]{2}{*}{ Station } & \multirow[t]{2}{*}{ Abbreviation } & \multicolumn{2}{|c|}{ Geographic location } & \multicolumn{2}{|c|}{$\begin{array}{l}\text { Centered dipole } \\
\text { Geomagnetic location }\end{array}$} \\
\hline & & Longitude & Latitude & Longitude & Latitude \\
\hline Tucson & TUC & $249.2^{\circ} \mathrm{E}$ & $32.2^{\circ} \mathrm{N}$ & $314.7^{\circ} \mathrm{E}$ & $40.3^{\circ} \mathrm{N}$ \\
\hline Boulder & $\mathrm{BOU}$ & $254.8^{\circ} \mathrm{E}$ & $40.1^{\circ} \mathrm{N}$ & $319.2^{\circ} \mathrm{E}$ & $48.9^{\circ} \mathrm{N}$ \\
\hline Glenlea & GLL & $262.0^{\circ} \mathrm{E}$ & $49.6^{\circ} \mathrm{N}$ & $326.2^{\circ} \mathrm{E}$ & $59.1^{\circ} \mathrm{N}$ \\
\hline Fredericksburg & FRD & $282.6^{\circ} \mathrm{E}$ & $38.2^{\circ} \mathrm{N}$ & $352.3^{\circ} \mathrm{E}$ & $49.1^{\circ} \mathrm{N}$ \\
\hline San Juan & SJG & $293.8^{\circ} \mathrm{E}$ & $18.1^{\circ} \mathrm{N}$ & $5.2^{\circ} \mathrm{E}$ & $29.1^{\circ} \mathrm{N}$ \\
\hline
\end{tabular}

50nT. The mean value of the field during all these intervals corresponds to the quiet value of the field for the given local time. The residuals have been rotated to $\mathrm{H}-\mathrm{D}-\mathrm{V}$ coordinate system. Thus the resulting values $\mathrm{dH}$, $\mathrm{dD}, \mathrm{dV}$, correspond to the disturbance due to current's intensification and/or disruption.

Magnetic variations observed at middle-latitude ground stations are dominated by the effects of fieldaligned currents. Kokubun and McPherron (1981) found a strong correlation between $\mathrm{H}$ variations at geostationary orbit and those at middle latitude stations on the same meridian. This correlation is interpreted as the station observing the effects of the substorm current wedge. The signatures at middle- and low-latitude stations differ from those in the auroral zone in that the $\mathrm{H}$ perturbation is dominated by the effects of fieldaligned current sheets, and not by the effects of the westward electrojet. A positive $\mathrm{H}$ perturbation occurs at middle- or low-latitude stations located inside the substorm current wedge. Low-latitude stations may also observe a large scale depression in the $\mathrm{H}$ component during periods of enhanced auroral activity. This corresponds to a growth of symmetric ring current. The $\mathrm{H}$ depression lasts many hours and is thus distinguishable from variations due to the substorm wedge.

Since for the purpose of our study we required that the events selected are covered by the GOES-5 and 6 satellites, the ground stations that are in the proper position to detect such a substorm disturbance are those located between $\sim 250^{\circ} \mathrm{E}$ and $\sim 300^{\circ} \mathrm{E}$ (geographic coordinates). The name, the abbreviation and the location of stations in geographic and centered dipole geomagnetic coordinates, are given in Table 2. A centered dipole field with the North Pole at $79.01 \mathrm{~N}$ and $288.98^{\circ} \mathrm{E}$ geographic coordinates is used for calculations. GOES-5 satellite is located between the Fredericksburg and San Juan meridian and rather closer to Fredericksburg, while GOES-6 is between the Boulder and Glenlea meridian. The spatial distribution of our observation points allowed us to make a detailed study of the azimuthal expansion of the substorm current wedge.

\section{Observations of the azimuthal expansion of the substorm current wedge}

For the purposes of this study we selected over 30 events that occurred in 1986 through 1988, according to the following criteria: (1) the substorms were selected to be isolated (2) during the selected events GOES-5 and
GOES-6 were close to local midnight to observe the SCW signatures; and (3) the events had to have full coverage from the four basic low-latitude observatories listed in Table 2. Although most of the events are consistent with the general results of this work, we present two in particular as the most characteristic events of our sample, showing clearly the azimuthal expansion of the SCW.

\subsection{Substorm event A: April 23, $19860400-0800$ UT}

The first event occurred on April 23, 1986 between 0400-0800 UT. Figure 1 presents the 1-min values of the $\mathrm{AL}$ index together with the $\mathrm{H}$-component from the middle- and low-latitude stations listed in Table 2. The $\mathrm{AL}$ variations indicate that the onset of the substorm, marked by the sudden intensification of the westward electrojet, occurred at $0551 \mathrm{UT}$. We conclude that this

Ground Signatures H(nT) component 860423

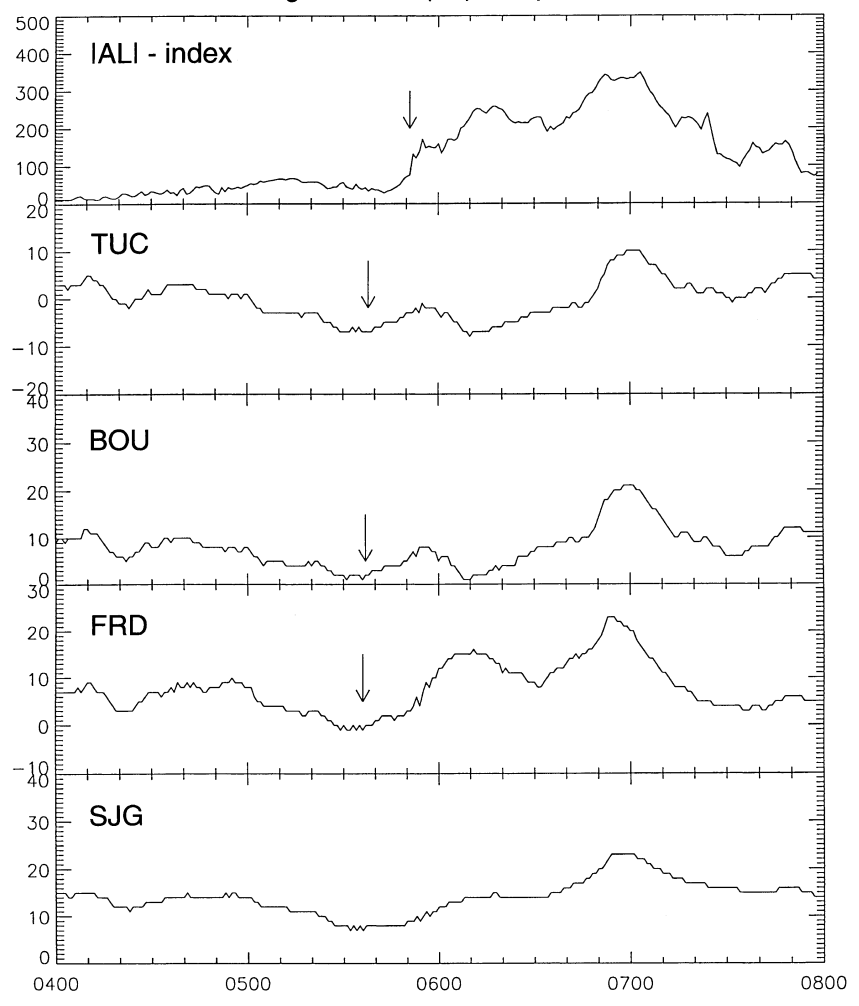

Fig. 1. The H-component magnetograms from four low-latitude stations, together with the AL index on April 23, 1986. The arrows indicate the onset time in each station 
might be the time of the formation of the westward electrojet which is part of the SCW. The low-latitude stations observed positive bays in the $\mathrm{H}$ component (marked with arrows in Fig. 1) starting at 0538 UT in Tucson, at 0537 UT in Boulder and at 0536 UT in Fredericksburg. A similar positive deflection of the $\mathrm{H}$ component is observed in San Juan. Nevertheless, the onset of the perturbation at this station cannot be accurately determined. Such positive bays are due to the integrated effects of the substorm current wedge (Kokubun and McPherron, 1981; Lopez and Lui, 1990). The D-component magnetograms from the lowlatitude stations are presented in Fig. 2. Together with the D-variation from ground stations we present, for comparison reasons, the D-variations from GOES satellites which will be discussed later in this section. The solid vertical line corresponds to the AL-onset time (0551 UT). The positive H-bays observed in Tucson and Boulder (Fig. 1) are accompanied by eastward deflection of the field, that appeared in the D magnetograms (Fig. 2) as positive deflection. The $\mathrm{D}$ component magnetogram from Fredericksburg station presents a positive deflection, accompanied by a negative deflection, indicating the center of the SCW was initially westward of the station and much later, at the recovery phase it has moved eastward of it. Boulder and Tucson were constantly west of the center of the current wedge,

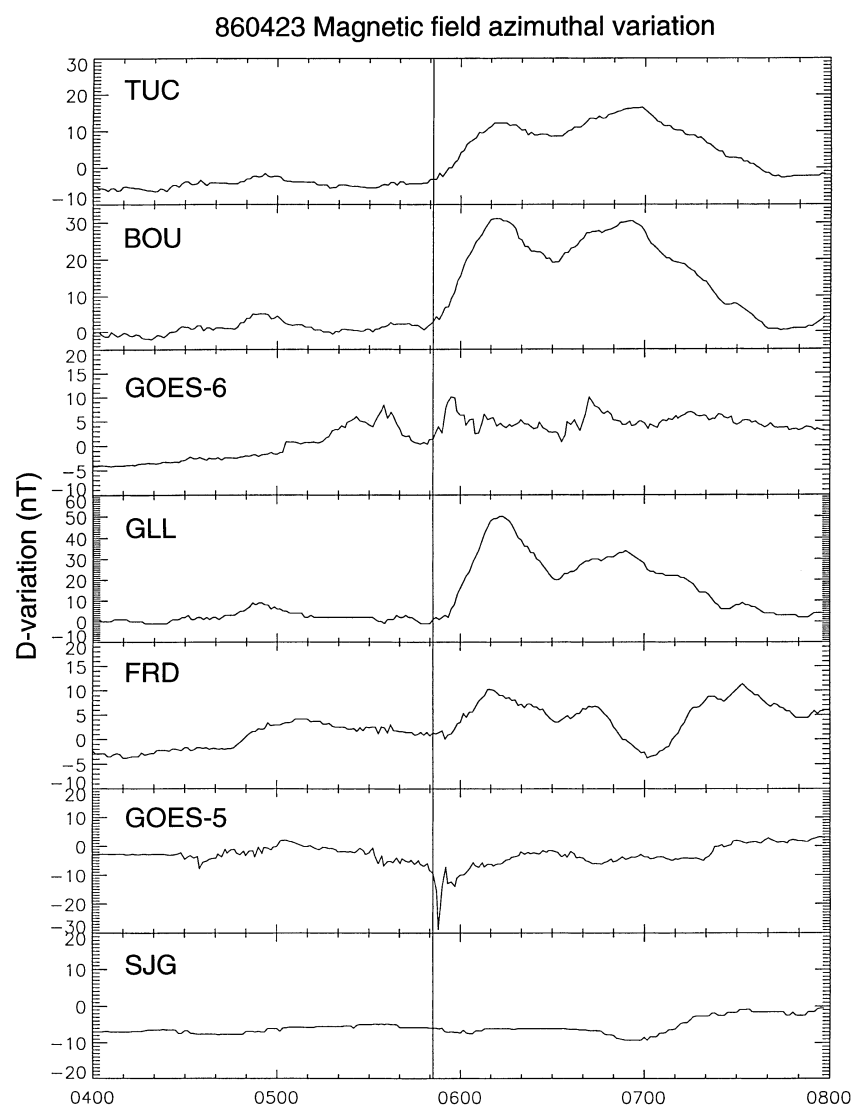

Fig. 2. The D-variation (in $\mathrm{nT}$ ) from low-latitude stations and from GOES satellites, on April 23, 1986. Tucson is the most westward point of our longitudinal chain, while San Juan is the most eastward point. The vertical line corresponds to the substorm onset whereas San Juan was constantly eastward of it. Thus, the onset sector is located between Fredericksburg (0030 MLT) and San Juan (0118 MLT) and rather closer to Fredericksburg.

The magnetograms from both GOES-5 and GOES-6 satellites are presented in Fig. 3a,b respectively, where the disturbance values $\mathrm{dH}, \mathrm{dD}$ and $\mathrm{dV}$ are plotted. A transient perturbation in the D-component of the magnetic field is a manifestation of field-aligned currents (FACs) in the magnetosphere, while the $\mathrm{H}$ - and $\mathrm{V}$ component disturbances are due to the cross-tail current effects. The perturbation of the magnetic field at GOES5 position, starts at 0430 UT with a deflection recorded in all components. Individual ground stations near the GOES-5 meridian do not detect any perturbation associated with the SCW at this time. The magnetic field disturbances were detected mainly at GOES-5 location, whereas the D-component disturbances measured by GOES- 6 at this time were negligible. This suggests that the disturbances detected are caused by field-aligned currents associated with a small-scale substorm wedge and not by the effects of large-scale current systems. An increase in the strength of the crosstail current would also explain such a negative $\mathrm{dD}$ perturbation in GOES-5. This might happen during the growth phase where the magnetic field in geostationary orbit is more tail-like than the quiet time configuration, which implies that the cross-tail current is, in fact, stronger than at quiet times. But since the growth phase does not start until 0500 at GOES-5 this is not a likely explanation for our case. A third possible scenario, to interpret this localized negative D-perturbation, might be the rapid movement of the satellite relative to the current layer. Since it is accompanied by drastic changes in all components, this might be an acceptable explanation. At 0500 UT GOES-5 measures a decrease in $\mathrm{dH}$ which indicates the growth of the tail currents just prior to the local onset of the substorm, determined to be at 0553 UT, according to GOES-5 H-field recovery. The growth of the tail currents is also evident in the decreasing $\mathrm{dV}$ at GOES-5 starting at $0500 \mathrm{UT}$. At 0553 UT GOES-5 measures perturbations associated with the substorm wedge formation, leading to the field dipolarization. Clear indications can be seen in the $\mathrm{dH}$ component whose absolute value decreases sharply and in the $\mathrm{dD}$ component whose negative peak at $0553 \mathrm{UT}$ coincides with the field dipolarization. The constantly negative perturbations of the D-component indicate that GOES-5 is north of the center of the substorm wedge. We point out again that GOES-5 is almost on Fredericksburg meridian, whereas GOES-6 is between Boulder and Gillam and rather closer to Boulder. Fredericksburg has a positive D perturbation whereas GOES-5 shows a spiky negative perturbation. Boulder and Gillam present positive bays having its two maxima at $0610 \mathrm{UT}$ and at 0655 UT. GOES-6 presents a transient positive peak at 0558 UT and a second one at 0642 UT. It appears that $\mathrm{D}$ perturbation at synchronous orbit is more transient than that on the ground in approximately the same meridian, indicating that the D-perturbation can be highly localized at synchronous orbit. 
23 April 1986, GOES5 LT=UT+19

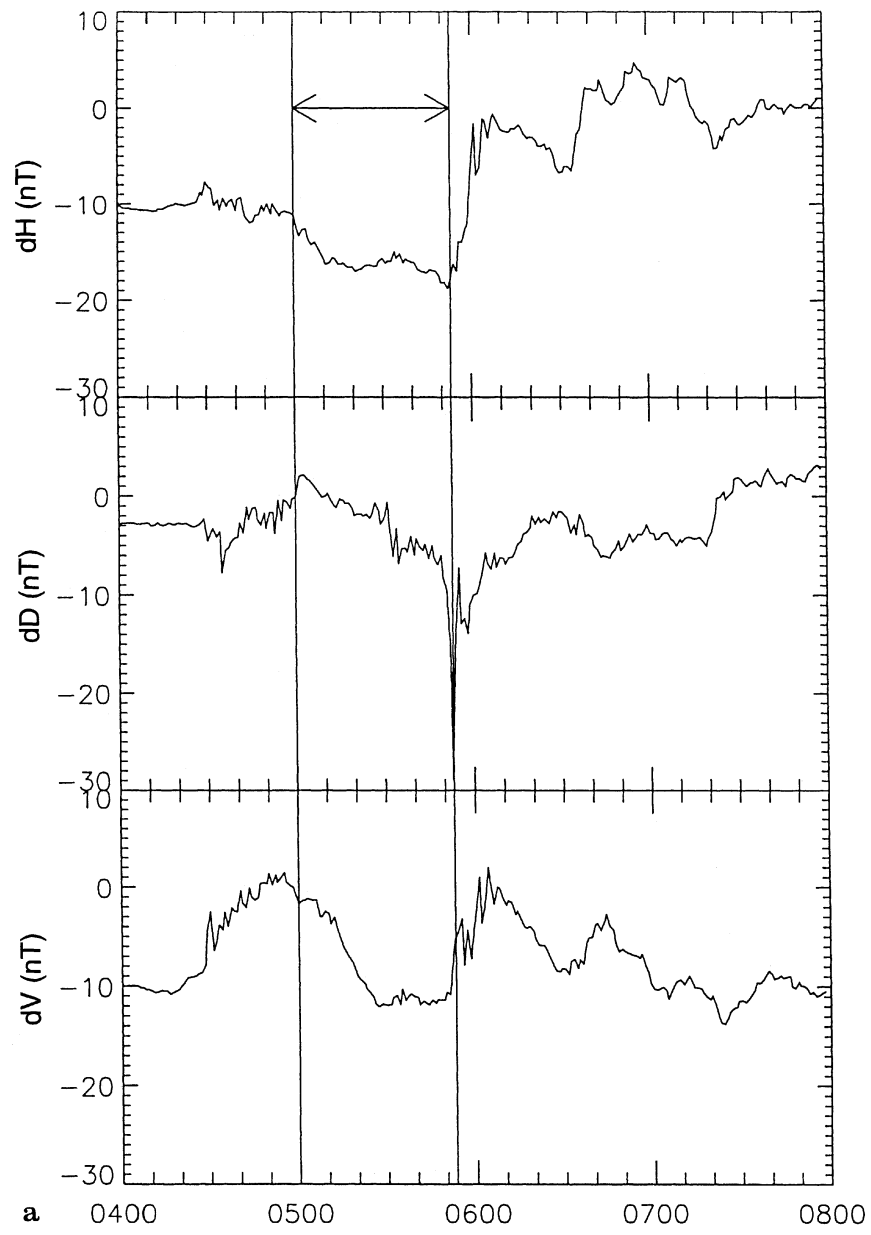

Fig. 3.a Magnetic field disturbance data from GOES-5 in VDH coordinates on April 23, 1986. The interval between the two lines at $0500 \mathrm{UT}$ and 0553 UT corresponds to the growth phase. At 0553 UT GOES-5 detects the dipolarization of the field. b Magnetic field

Dipolarization was first recorded by GOES- 5 at 0553 UT (0053 MLT) while at the same time the change into a tail-like configuration was still in progress at GOES-6. Eventually, GOES-6 recorded the dipolarization at 0607 UT (2255 MLT), evidenced from the simultaneous increase in $\mathrm{dV}$ and $\mathrm{dH}$ (Fig. 3b). The $\mathrm{dD}$ component at GOES-6 has positive peaks at the time that upward field-aligned currents of the substorm current wedge pass over the GOES-6 satellite. To give a summary of the event we noted in Fig. 3a,b the duration of the growth phase seen by each satellite by a horizontal line. In general during this event, the D-perturbations, as well as the field changes, are quite asymmetrical at GOES-5 and GOES-6. Given that the onset sector of the SCW formation was estimated to be for the ground signatures between 0030 and 0118 MLT, and given that GOES-6 is westward of GOES-5 the time delay of $\sim 14$ min in dipolarization detection, indicates the westward propagation of the SCW. The position of the two satellites is given in a local time versus radial distance representation in Fig. 4. The * point indicates the possible location of the sector of the SCW formation. These observations indicate first that GOES-5 was very close to the distur-

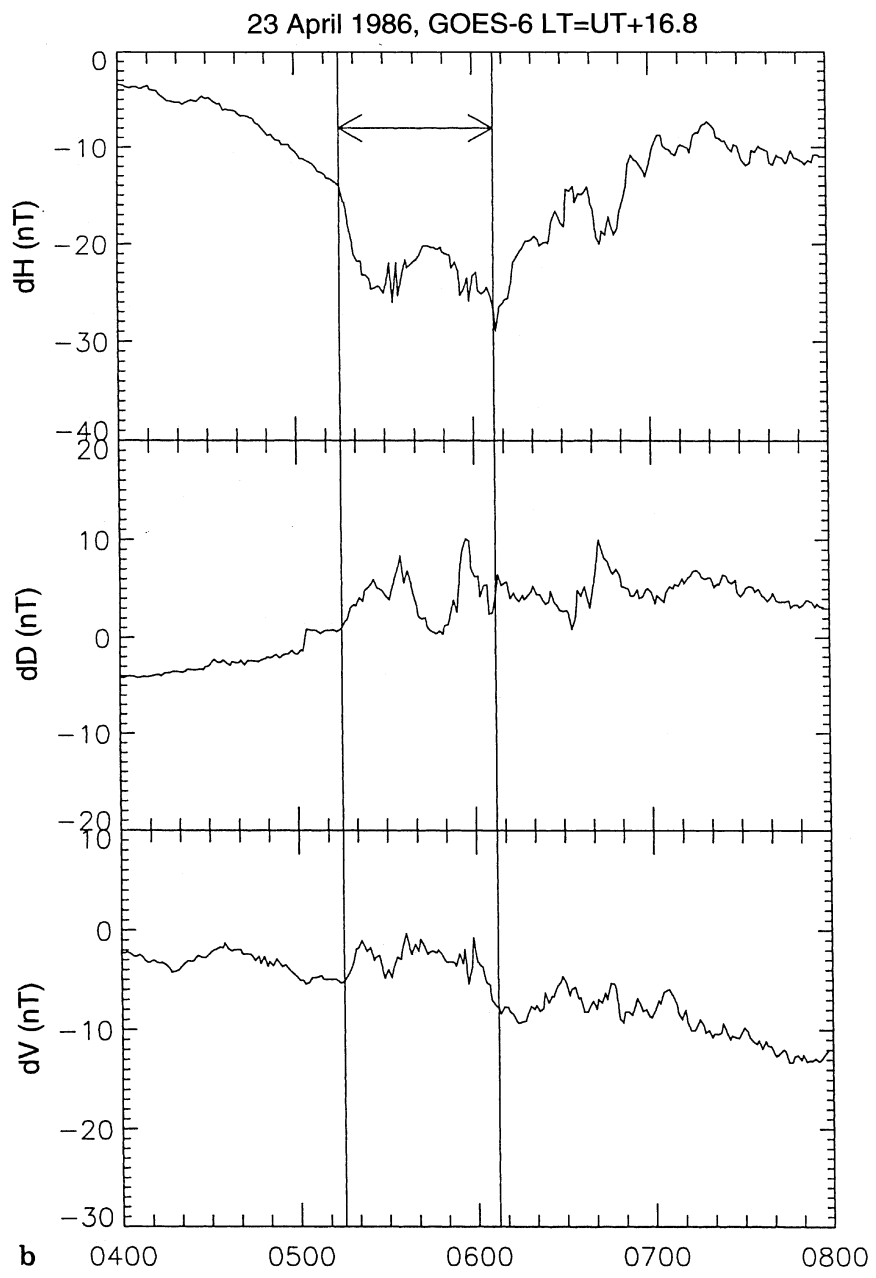

disturbance data from GOES-6 in VDH coordinates on April 23, 1986. The interval between the two lines at 0513 UT and 0607 UT corresponds to the growth phase at GOES-6 position. At 0607 UT GOES-6 detects the dipolarization of the field

bance region, which is referred to as the onset sector and that the two satellites were initially on different sides of it, GOES-5 eastward and GOES-6 westward of it. The center of the onset sector is then suggested to be within 0030 and 0050 MLT i.e., between Fredericksburg meridian and GOES-5 meridian.

To have a global view of the disturbances taking place in the magnetosphere, we present in Fig. 5 the north to south component of the interplanetary magnetic field from IMP8, in $15.5 \mathrm{~s}$ resolution, the energy consumption rate in the ionosphere, $U_{\mathrm{I}}$, and the magnetic energy density calculated at GOES-5 and GOES-6 position. According to Akasofu (1981), the energy consumption rate in the ionosphere $U_{\mathrm{I}}$ $\left(=3 \times 10^{15} \times \mathrm{AE}, \mathrm{erg} / \mathrm{s}\right)$ is given by the sum of the kinetic power of auroral particles being lost in the ionosphere due to the collision $\left(U_{A}=\mathrm{AE} \times 10^{15}, \mathrm{erg} / \mathrm{s}\right)$ and of the Joule heating associated with electric current flow in the resistive ionosphere $\left(U_{J}=2 \times \mathrm{AE} \times 10^{15}\right.$ $\mathrm{erg} / \mathrm{s})$. We note a southward turning of the IMF at 0450 UT, that arrived in the vicinity of the magnetosphere with a delay time of $\sim 10 \mathrm{~min}$, causing a smooth increase of the magnetic energy density starting at $0500 \mathrm{UT}$ at 
$\underline{860423 \text { at } 0550 \mathrm{UT}}$

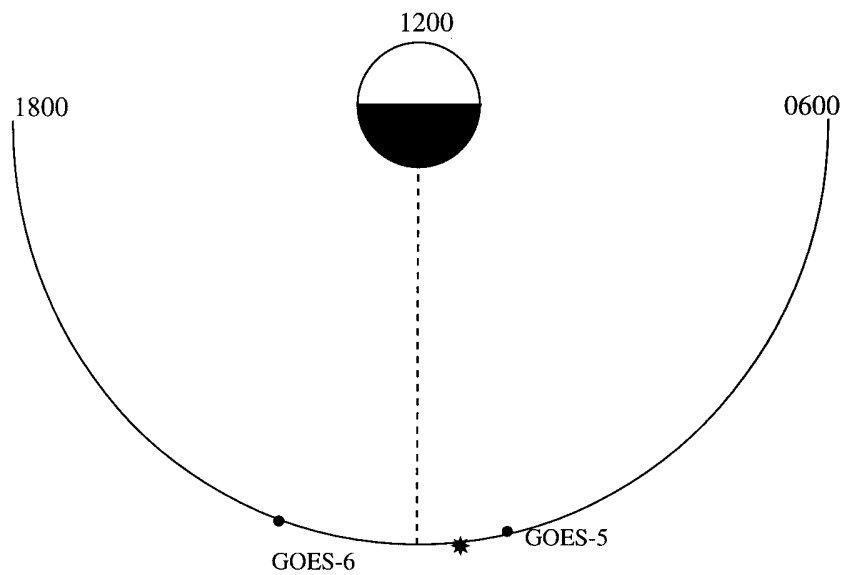

Fig. 4. The position of GOES-5 and GOES- 6 satellites is given in a local time versus radial distance representation for the April 23, 1986 event, at 0550UT when the AL onset is detected. The * point indicates the possible location of the sector of the initial SCW formation

860423

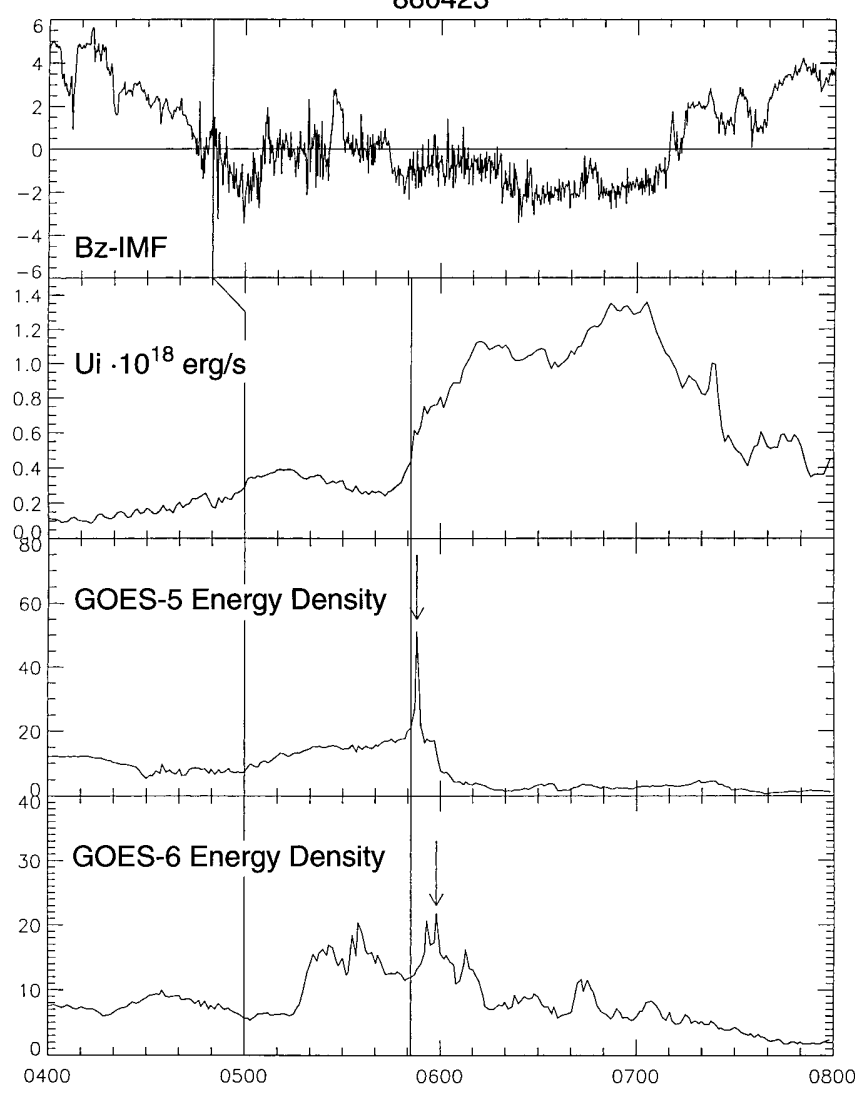

Fig. 5. From top to bottom panels: the interplanetary magnetic field $B z$ component from IMP8 spacecraft (in 15.5 s resolution), the energy consumption rate in the auroral ionosphere $U_{\mathrm{I}}$ and the magnetic energy density from GOES-5 and GOES-6 for the April 23, 1986 event. The southward turning of the IMF at 0450 UT caused the start of the substorm at 0500 UT on the ground. The directly driven and the loading mechanism as well are in progress until $0551 \mathrm{UT}$, where the onset at AL index is detected (indicated by the second vertical line). The unloading of the stored energy occurred at 0553 UT from GOES5 and at 0607 UT from GOES-6
GOES-5 position and simultaneously affected the magnetic field recorded from auroral oval observatories, causing an increase of the energy consumption rate in the auroral ionosphere. At GOES-6 position, the magnetic energy density starts to increase at 0517 UT. According to the description of this series of observations, during the time interval 0500-0550 UT, a deposition of energy occurred in the inner magnetosphere (evidenced from the gradual increase of magnetic energy density at GOES-5 and GOES-6) and at the same time an amount of energy is dissipated in the high-latitude ionosphere (purely caused by solar wind parameters, IMF $B z<0)$. Therefore, this interval is characterized by the driven process. At $0551 \mathrm{UT}$ the onset of the substorm is detected by the drastic decrease of the ALindex indicating the formation of the portion of the westward electrojet, the part of the SCW in the midnight ionosphere, marking the onset of the unloading process. Two minutes later, at $0553 \mathrm{UT}$, an event of energy release was recorded at GOES-5 location. At GOES-6 position the decrease of the magnetic energy density starts at $0600 \mathrm{UT}$, that is $7 \mathrm{~min}$ after the unloading process recorded by GOES-5.

The delay time between GOES-5 and GOES- 6 in recording the onset of the loading and of unloading process, is expected considering that GOES5 was eastward of GOES-6 and much closer to the initial formation of SCW as indicated in Fig. 4.

An important result is that the two localized release processes noted with arrows in Fig. 5, have been detected with a small time delay $(2 \mathrm{~min}$ and $7 \mathrm{~min}$ ) from the onset of the expansion phase, as determined by the AL-index. This suggests that the changes in the magnetic field energy density, at these two isolated points, follow in general the global energy change derived from AE-index.

\subsection{Substorm event B: May 7, $19860500-0900$ UT}

The AL index together with the $\mathrm{H}$ - component magnetograms from the four ground stations listed in Table 2, are presented in Fig. 6. The westward electrojet intensification which marks the SCW formation is detected at 0640 UT. The positive bay at $\mathrm{H}$-component (indicated by arrows in Fig. 6) is detected at 0639 UT in Tuscon, at 0637 UT in Boulder, at 0635 UT in Fredericksburg and at 0640 UT in San Juan. The D- traces from low-latitude stations as well as from GOES are presented in Fig. 7. The solid vertical line corresponds to the AL onset at 0640 UT. It is obvious that Tucson and Boulder are westward of the current wedge center, since the positive bay at $\mathrm{H}$-component is associated with an eastward deflection of the field (positive D perturbation), whereas Fredericksburg and San Juan are eastward of it, since the positive H-bay is associated with a negative bay of the D-component. From the time delay of the positive $\mathrm{H}$-bay observation in each one of the stations it is obvious that the disturbance arrived first in Fredericksburg and consequently propagated both westward, detected in Boulder and in Tucson and eastward, 
Ground Signatures H(nT) component 860507

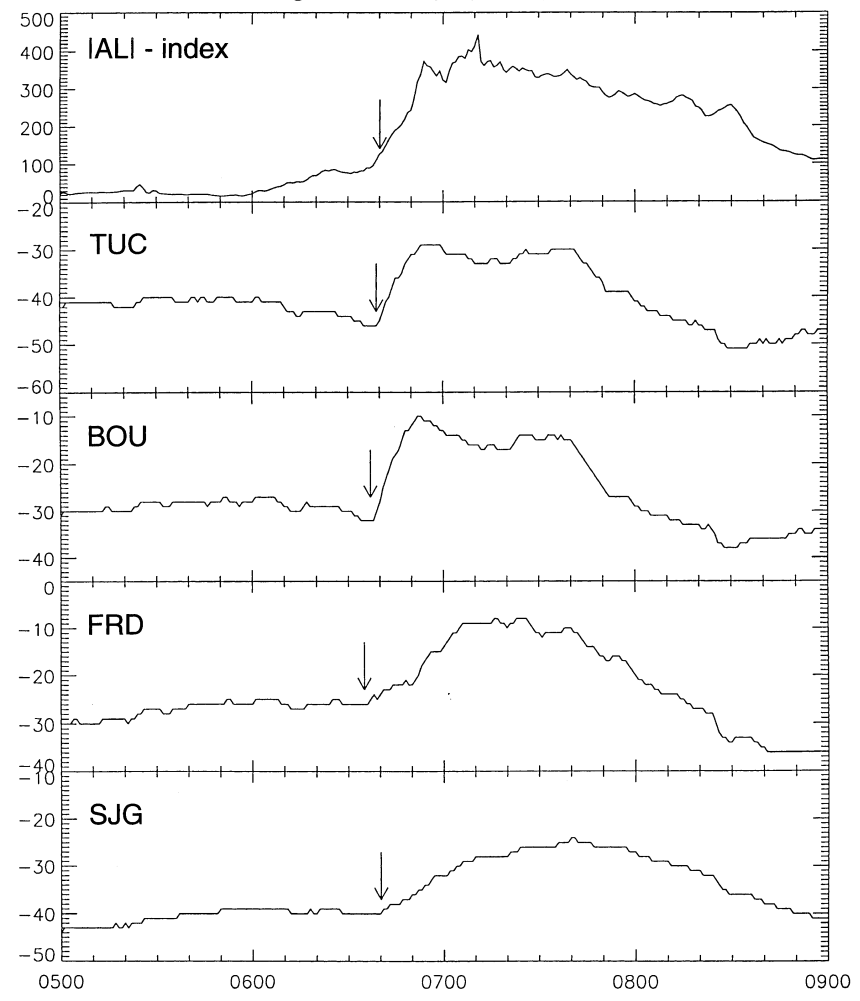

Fig. 6. The H-component magnetograms from four low-latitude stations, together with the $|\mathrm{AL}|$ index on May 7, 1986. The arrows indicate the onset time in each station

detected in San Juan. From the D-component magnetograms it is inferred that the center of the current disruption it is located somewhere between Fredericksburg and Boulder in longitude, and most probably closer to Boulder.

The one minute resolution data of the disturbed field $\mathrm{dH}, \mathrm{dD}$, and $\mathrm{dV}$ component from GOES-5 and GOES-6 are presented in Fig. 8a,b respectively. At 0640 UT, where the onset of the substorm was detected by ALindex (see Fig. 6), GOES-6 was at 2328 MLT while GOES-5 was at 0140 MLT. Since GOES-6 was very close to the local midnight meridian it will detect first the effects of the cross-tail current intensification and disruption. The inspection of the disturbances along the $\mathrm{V}$ and $\mathrm{H}$ components shows a clear change of the magnetic field geometry to a more tail-like configuration prior to the local onset, starting at 0540 UT at GOES-6 and at 0600 UT at GOES-5. The first indication of FACs appearance detected at 0612 UT in GOES-6 sector with an eastward perturbation in D-component, while in GOES-5 sector the FACs' signatures appear simultaneously with a westward perturbation. This implies the two satellites were initially on different sides of the disturbance region. Given that both satellites are north of the neutral sheet, this comment confirms that GOES-5 was eastward of the disturbance region, namely the onset sector, while GOES-6 was westward of it. Also, both of them are equatorward of the center of the FAC, although GOES-5 seems to be closer to it, since it recorded larger disturbances. Dipolarization was first

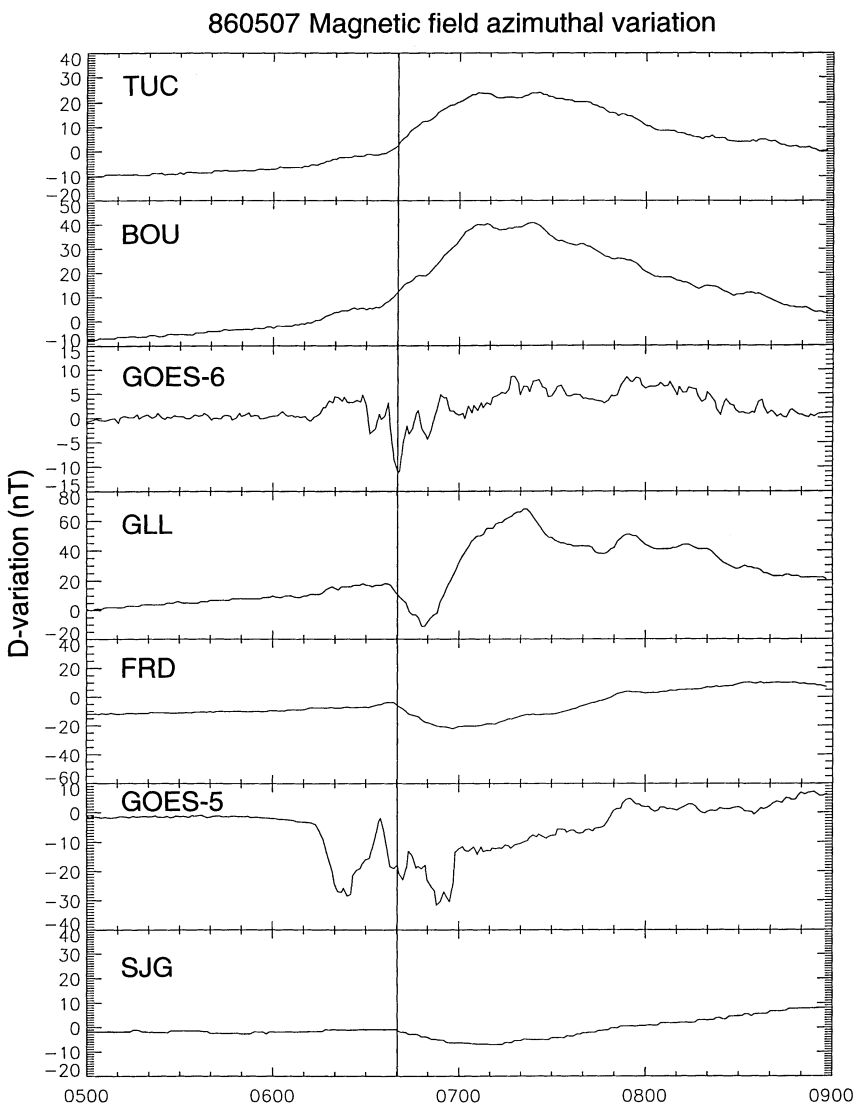

Fig. 7. The D-component variations (in nT) from low-latitude stations and from GOES satellites as well, for May 7, 1986. TUC is the most westward point of our chain, while SJG is the most eastward. The vertical line corresponds to the substorm onset time

recorded by GOES- 6 at 0641 UT, while at the same time, the change into a tail-like configuration was still in progress at GOES-5. Eventually GOES-5 recorded the dipolarization at $0653 \mathrm{UT}$.

From the comparison between GOES D-traces and D-variation signatures recorded on the ground (Fig. 7) the following observations are extracted: GOES-5 detects generally a negative $\mathrm{D}$ perturbation with three distinct negative peaks. On the other hand Fredericksburg detects a smooth negative bay. GOES-6 detects a sharp negative D perturbation centered at the time of the AL-onset whereas Boulder detects a smooth large positive bay.

The duration of the growth phase seen in each of the two satellites is noted in Fig. 8a,b respectively by a horizontal line. From this analysis it is inferred that the onset sector was very close to GOES-6 meridian and most probably between 2330 and 2400 LT. The position of the two satellites together with the onset location (marked with a* symbol) are presented in Fig. 9.

To have an overall view of the energy transfer from the inner magnetosphere to the auroral ionosphere, we present in Fig. 10 the AU and AL indices (upper two panels) along with the energy consumption rate in the auroral ionosphere, $U_{\mathrm{I}}$, and the magnetic energy density from GOES-6 and GOES-5. GOES- 6 could be used as a measure of the variation of the energy stored in the inner 
7 May 1986, GOES5 LT=UT+19

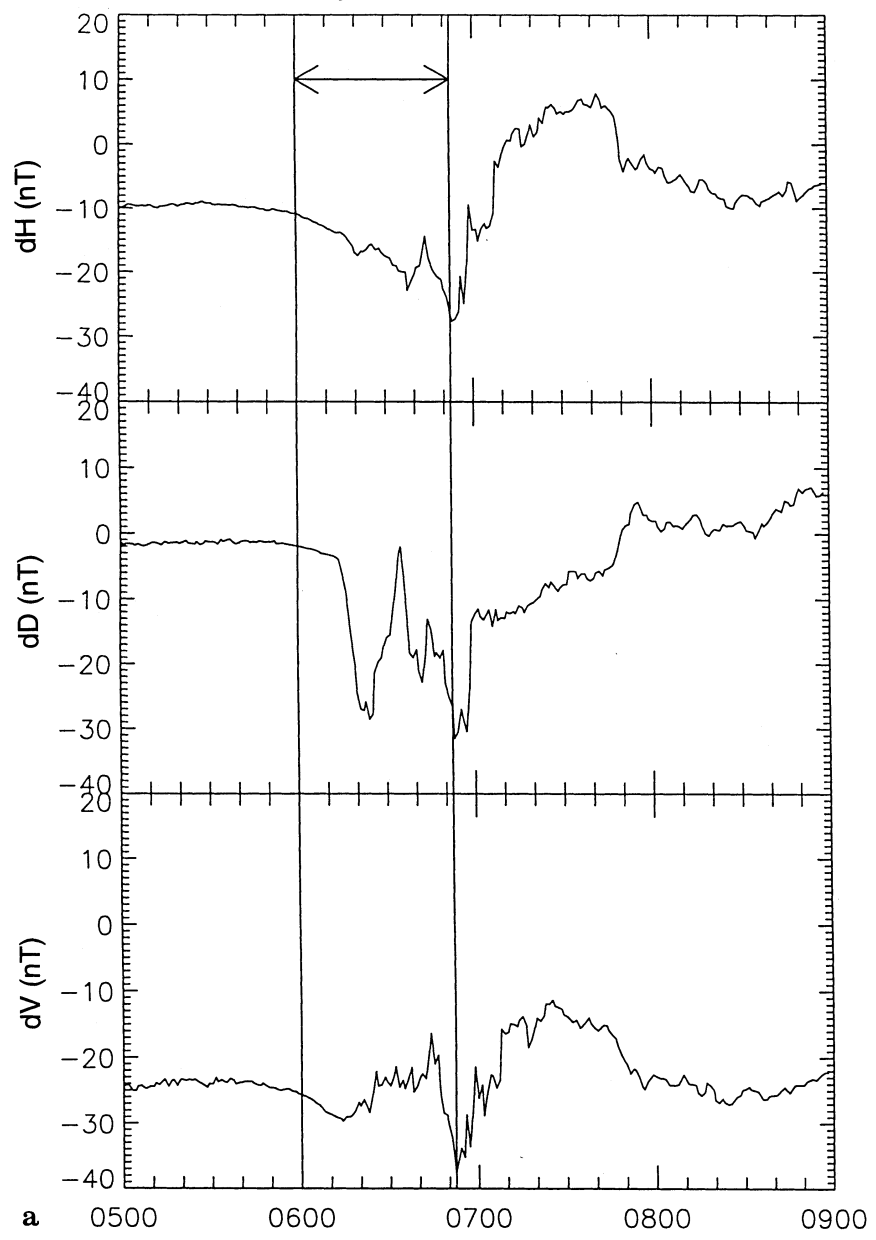

Fig. 8. a Magnetic field disturbance data from GOES-5 in VDH coordinates on May 7, 1986. The interval between the two lines at 0600 UT and 0653 UT corresponds to the growth phase at GOES-5 position. At 0653 UT GOES-5 detects the dipolarization of the field.

\section{$\underline{860507 \text { at 0640UT }}$}

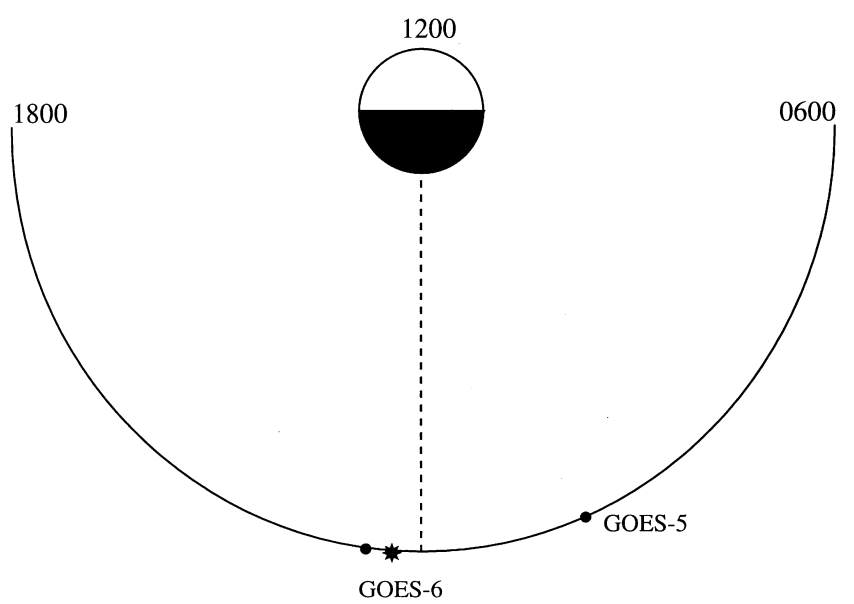

Fig. 9. The position of GOES-5 and GOES-6 satellites is given in a local time versus radial distance representation for the May 7, 1986 event, at 0640 UT when the AL onset is detected. The * point indicates the possible location of the sector of the initial SCW formation
7 May 1986, GOES6 LT=UT+16.8

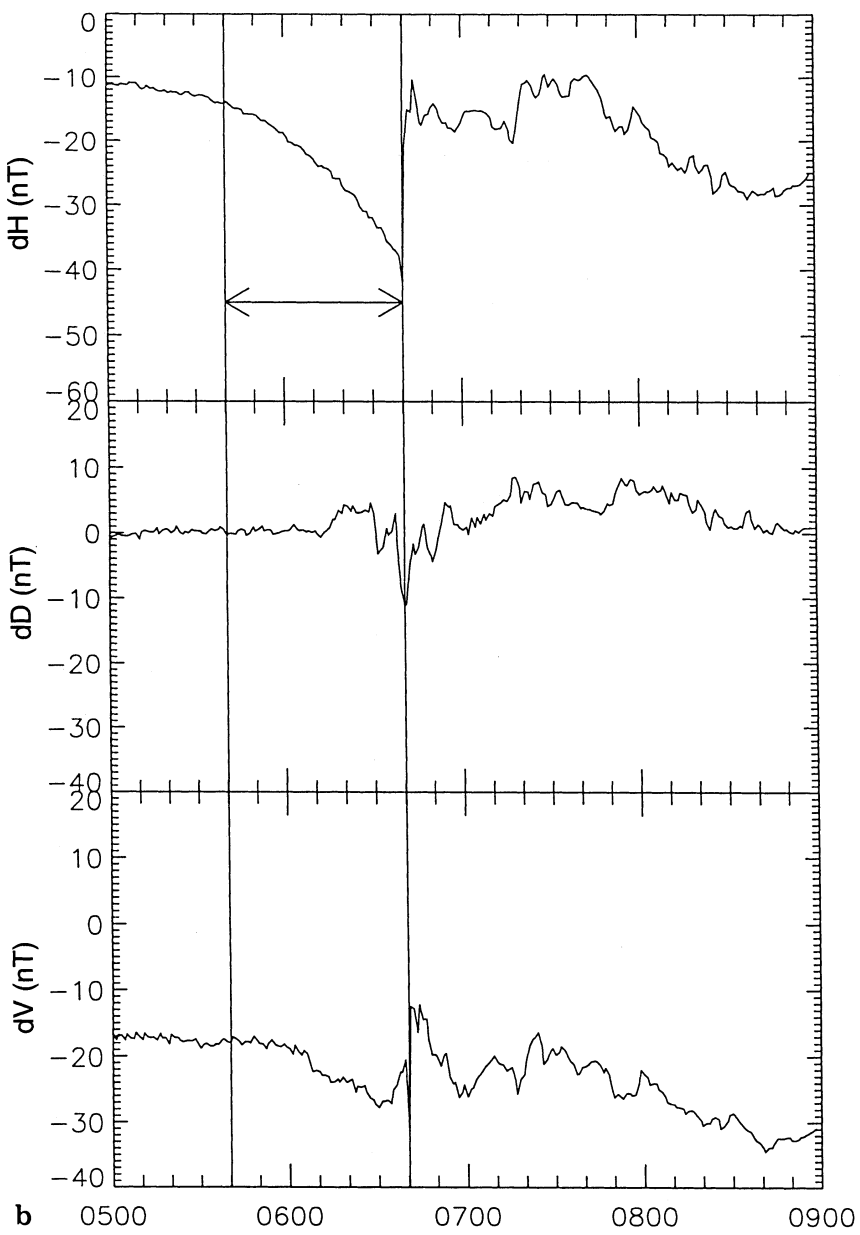

b Magnetic field disturbance data from GOES-6 in VDH coordinates on May 7, 1986. The interval between the two lines at 0540 UT and 0640 UT corresponds to the growth phase at GOES-6 position. At 0640 UT GOES- 6 detects the dipolarization of the field

magnetosphere since during the growth phase (the interval between the two vertical lines), the energy density increases at GOES-6 position indicating loading of energy, whereas at the onset of the expansion phase (0640 UT) an event of sudden release of energy has been recorded. On the other hand GOES-5 detects three localized events of energy release, one exactly at the time of substorm onset and two more events around this characteristic time. The different behaviour of the energy variation, at these two different locations of the geosynchronous orbit, is due to the position of the two satellites with respect to local midnight. GOES-6 is located at midnight, whereas GOES-5 is far eastward.

\section{Velocity of the azimuthal expansion of the substorm current wedge}

The velocity of the azimuthal expansion of the SCW has been estimated using the time delay of the appearance of the disturbance between two low-latitude observatories. The results have been based on the analysis of the isolated substorms listed in Table 3 where, together with 


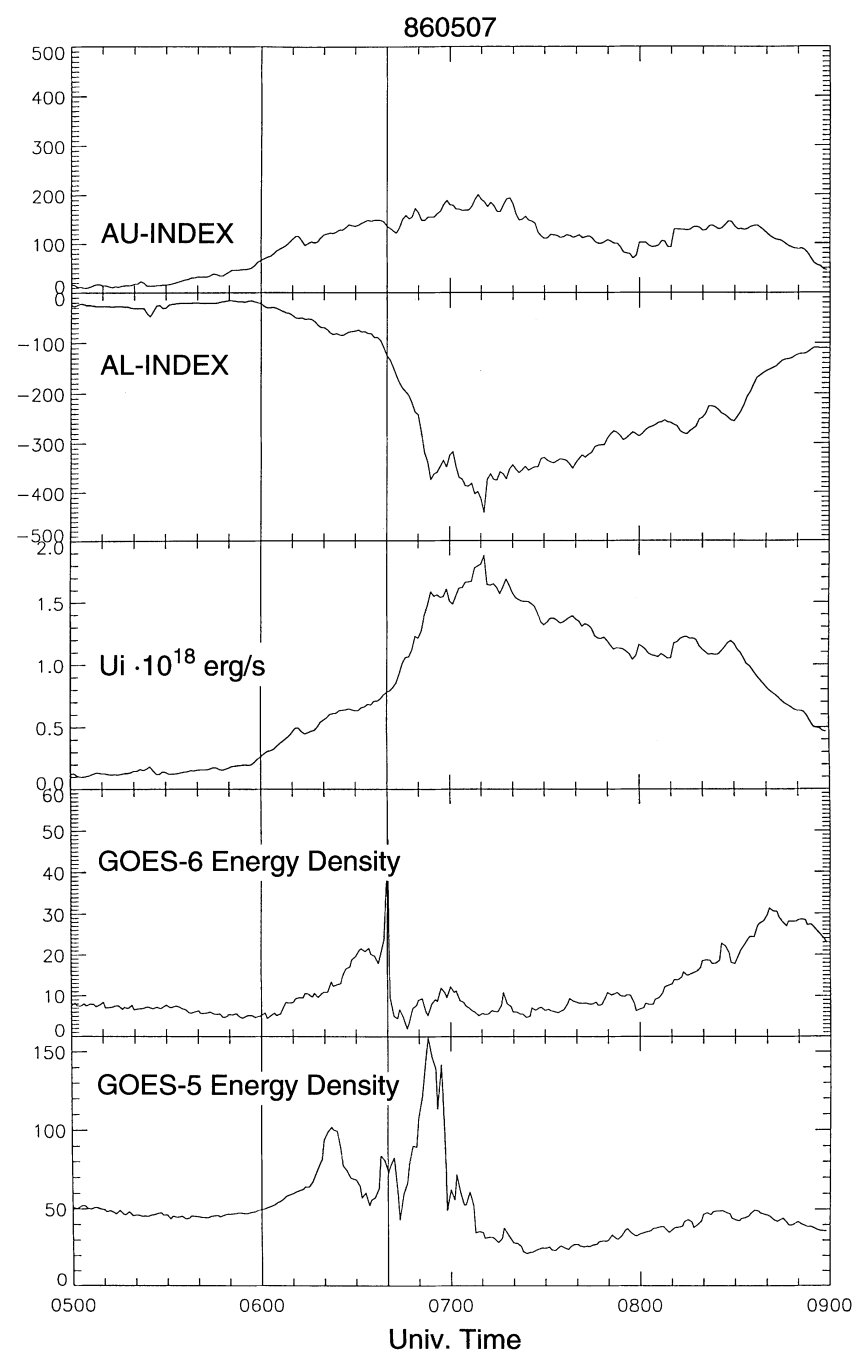

Fig. 10. From top to bottom panels: the AU and AL index, the energy consumption rate in the auroral ionosphere and magnetic energy density from GOES-6 and GOES-5 satellites for the May 7, 1986 event. The two vertical lines indicate the substorm growth phase according to the AL and AU index

the time interval of substorm occurrence, we give the maximum value of the AE index. The events selected were of moderate intensity since the maximum value of $\mathrm{AE}$ index was between $400 \mathrm{nT}$ and $600 \mathrm{nT}$. We have grouped our results into three sets: the first corresponds

Table 3. A list of the substorms selected to estimate the velocity of the azimuthal expansion of the SCW

\begin{tabular}{llll}
\hline Date & Time interval & $\begin{array}{l}\text { Onset } \\
(\mathrm{UT})\end{array}$ & $\begin{array}{l}\text { Maximum } \\
\text { AE-index }\end{array}$ \\
\hline January 25, 1986 & $0200-0600 \mathrm{UT}$ & 0400 & $600 \mathrm{nT}$ \\
April 1, 1986 & $0800-1200 \mathrm{UT}$ & 0900 & $550 \mathrm{nT}$ \\
April 23, 1986 & $0400-0800 \mathrm{UT}$ & 0545 & $450 \mathrm{nT}$ \\
May 7, 1986 & $0500-0900 \mathrm{UT}$ & 0640 & $580 \mathrm{nT}$ \\
March 14, 1987 & $0300-0700 \mathrm{UT}$ & 0500 & $600 \mathrm{nT}$ \\
March 29, 1987 & $0500-0800 \mathrm{UT}$ & 0605 & $520 \mathrm{nT}$ \\
June 24, 1987 & $0600-1000 \mathrm{UT}$ & 0650 & $470 \mathrm{nT}$ \\
March 2, 1988 & $0700-1000 \mathrm{UT}$ & 0730 & $400 \mathrm{nT}$ \\
\hline
\end{tabular}

to the velocity of the disturbance propagation based on the time delay of the disturbance appearance between BOU to FRD. The two stations are located approximately at the same latitude and are separated by $\sim 30^{\circ}$ in longitude. The second set corresponds to the velocity of the disturbance propagation between BOU and TUC which are separated by $5^{\circ}$ in longitude. Finally, the third set of results presents the velocity of the eastward propagation of the disturbance based on the time delay of the disturbance appearance between FRD and SJG, which are separated in longitude by $13^{\circ}$.

To obtain velocity values better compared to each other, the estimated velocities have been normalized with respect to the greater value of each data set. The results are plotted in Fig. 11. A distance-weighted least squares fit is overplotted to show the general trend of our data points. It is evident that the propagation of the disturbance decelerates from its initiation point toward dusk or dawn. Moreover, the drastic decrease of the velocity with the azimuthal distance from the location of the disturbance initiation, indicates that the energy release is a localized phenomenon. There is also evidence that the onset of the perturbation occurs $\sim 30$ min before local midnight and travels toward the west with velocities greater that those expanding the wedge eastward.

\section{Discussion}

The main objective of this work is to study the azimuthal expansion of the current wedge and to give an estimate for the velocity by which the SCW expands towards dawn and dusk. We give details of two of the clearest examples of the azimuthal expansion of the SCW, but the results seen are consistent with all the other events studied.

At the onset of the first substorm GOES-5 was closer to midnight, than GOES-6 (see Fig. 4). Because of GOES relative position, GOES-5 detected the field dipolarization first, while GOES-6 recorded it $\sim 14 \mathrm{~min}$ later. From the comparison of the magnetic field

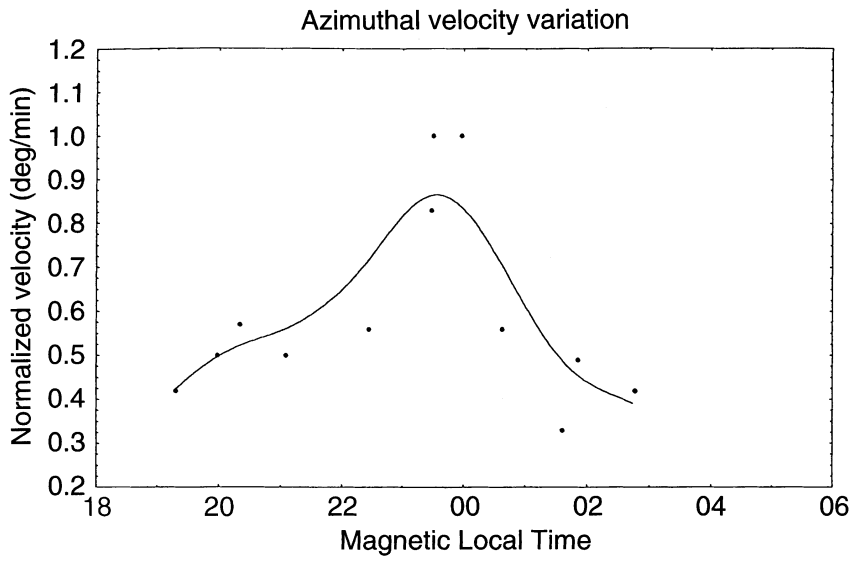

Fig. 11. The variation of the longitudinal expansion velocity of the substorm current wedge versus magnetic local time. A distance weighted least squares fit is overplotted to show the general trend of our data points 
disturbances from geosynchronous altitudes with the ground magnetic field data, it is evident that the substorm current wedge is formed in a narrow longitudinal sector between $0030 \mathrm{LT}$ and $0050 \mathrm{LT}$ and spreads westward and eastward as well. The overview of this event is given in Table 4. GOES-5 detected the onset with a time delay of 2 min resulting in an eastward expansion of the substorm current wedge in the geosynchronous orbit with an average velocity of $1.6^{\circ}$ min. On the other hand, GOES-6 which was to the west of the initial location of the SCW formation, detected the onset with a time delay of $16 \mathrm{~min}$. Since the traveling disturbance covers a distance of $24^{\circ}-29^{\circ}$, the average velocity was estimated to be $1.7^{\circ} / \mathrm{min}$.

At the onset of the second substorm presented in detail, GOES-6 was very close to midnight, while GOES-5 was eastward of it (Fig. 9). Thus, the field dipolarization was detected first by GOES-6 almost instantaneously with the AL onset. Afterwards, GOES5 detected the dipolarization with a time delay of $13 \mathrm{~min}$. From the comparison of geosynchronous and ground magnetic field data it is clear that the substorm current wedge is formed in a narrow region (between 2330 LT and 2400 LT) westward of the local midnight and spreads towards the west and the east. The overview of this event is presented in Table 5. Since GOES-6 detected the onset simultaneously with the AL-index's sharp decrease, we cannot estimate a velocity for the westward propagation of the SCW for this event. GOES-5 detected the field dipolarization with a time delay of $13 \mathrm{~min}$. Thus, the disturbance is traveling eastward, covering an azimuthal distance of $28^{\circ}-36^{\circ}$ in $13 \mathrm{~min}$. This gives us an average eastward velocity of $2.5^{\circ} / \mathrm{min}$.

Table 4. The overview of the substorm that occurred on April 23, 1986, between 0500 and 0800 UT

- GOES-6 dipolarization detection at $0607 \mathrm{UT}$ (2255 LT)

- AL onset at $0551 \mathrm{UT}$ - GOES-5 dipolarization detection at $0553 \mathrm{UT}$ (0053 LT)
Westward propagation of the SCW formation from the onset sector to GOES-6 location in $16 \min$

Eastward propagation of the SCW formation from the onset sector to GOES-5 location in $2 \mathrm{~min}$

Table 5. The overview of the substorm that occurred on May 7, 1986, between 0600 and 0900 UT

- GOES-6 dipolarization detection at $0640 \mathrm{UT}$ (2328 LT)

- AL onset at $\sim 0640 \mathrm{UT}$ - GOES-5 dipolarization detection at $0653 \mathrm{UT}$ (0153 LT)
The westward propagation of the SCW formation occurred almost instantaneously, since GOES-6 was very close to the SCW onset sector

Eastward propagation of the SCW formation from the onset sector to the GOES-5 location in $13 \mathrm{~min}$
Although the uncertainties of the estimated velocities are very high due to the uncertainty in the determination of the SCW location, we can see a trend of higher velocities observed towards the west. This result was based only on the velocities computed for the first event. In the second event, the value of $2.5^{\circ} / \mathrm{min}$ estimated for the eastward velocity, does not necessarily show faster propagation towards the east, since the westward velocity for the same event can be even higher. To compare the eastward with the westward velocities we should refer to values computed for the same event, since the magnitude of the velocity depends on the amount of energy dissipated in each substorm. The magnetospheric conditions required for the expansion of the current disruption are one of the most important problems of substorm mechanisms.

Concerning the average magnitude of the expansion speed, Kokubun and McPherron (1981) estimated for one case (July 14, 1974) that the longitudinal expansion speed of the current wedge was $\sim 2^{\circ} / \mathrm{min}$, which is also the average expansion speed determined by Lopez et al. (1988b). For another case, Lopez and Lui (1990) estimated a much higher propagation speed $\sim 13^{\circ} / \mathrm{min}$. Similar longitudinal expansion speeds have been observed during other events by Nagai (1982) and by Arnoldy and Moore (1983).

From the analysis presented here it is obvious that the magnitude of the azimuthal velocity depends strongly on the local time. The pattern of the velocity modulation versus local time given in Fig. 11 shows clearly that the disturbance observed on the ground decelerates from its initiation point (near local midnight) towards dawn and dusk. The velocities measured near 1800 LT and 0600 LT may be one third of the propagation velocity of the disturbance near local midnight. This might explain the large deviations of the propagation speed referred to up now in various papers cited in the previous paragraph. The drastic decrease of the velocity with the azimuthal distance from the location of the disturbance initiation, indicates that the energy release is a localized phenomenon.

One important result of our study is the determination of the restricted local time sector in which the SCW initially develops. The center of this sector is located between 0030 and 0050 LT for the first event and between 2330 and $0000 \mathrm{LT}$ for the second one, giving an initial width of the current wedge less than $15^{\circ}$. Previous studies have established that the SCW begins in a longitudinally narrow region. Nevertheless it was believed that the onset sector was centered on average at $\sim 2300$ LT and subsequently expands in local time (Nagai, 1982; Arnoldy and Moore, 1983; Lopez et al., 1988b Tsagouri et al., 1996). This is in agreement with the location determined for the second event. Contrary to this expectation, the analysis of the first substorm gave us an onset sector that was centered far eastward, located between 0030 and $0050 \mathrm{LT}$.

Finally, the comparison between GOES and ground $\mathrm{D}$-variations shows that $\mathrm{D}$-disturbances at synchronous orbit can be confined to regions near the field-aligned currents' meridians whereas D-disturbances are observ- 
able over a wider local time span on the ground. The same conclusion has been reported by Nagai (1987). The explanation proposed was that geosynchronous satellites are located near the dynamic current sheets which are longitudinally limited and thus observations are quite transient and highly dependent on the spacecraft position relative to the current sheets. Many currents however, are time- and space-integrated before being recorded by ground stations and thus these observations are less transient.

The major conclusion from this analysis is that the current disruption region expands both eastward and westward in the magnetotail, so that the location of major field-aligned currents flowing into the ionosphere shifts successively eastward, and the location of the currents flowing out of the ionosphere shifts successively westward.

Acknowledgements. This work was supported by the General Secretariat for Research and Technology of the Greek Ministry of Development.

Topical Editor K.-H. Glassmeier thanks a referee for his help in evaluating this paper.

\section{References}

Arnoldy, R. L., and T. E. Moore, The longitudinal structure of substorm injections at synchronous orbit, J. Geophys. Res., 88, 6213-6220, 1983.

Akasofu, S.-I., Magnetospheric substorms: a model, in Solar Terrestrial Physics, Part III, Ed. E. R. Dyer, p. 131, D. Reidel, Hingham, Mass., 1972.

Akasofu, S.-I., Energy coupling between the solar wind and the magnetosphere, Space Sci. Rev., 28, 121-190, 1981.

Baumjohann, W., Ionospheric and field-aligned current systems in the auroral zone: a concise review, Adv. Space Res., 2, 55, 1983.

Bogott, F. H., and F. S. Mozer, Nightside energetic particle decreases at the synchronous orbit, J. Geophys. Res. 78, 81198127, 1973.

Hesse, M., and J. Birn, On dipolarization and its relation to the substorm current wedge, J. Geophys. Res. 96, 19410, 1991.

Jacquey, C., J. A. Sauvaud, and J. Dandouras, Location and propagation of the magnetotail current disruption during substorm expansion: analysis and simulation of an ISEE multi-onset event, Geophys. Res. Lett. 18, 389, 1991.

Kaufmann, R. L., Substorm currents: growth phase and onset, $J$. Geophys. Res. 92, 7471-7486, 1987.

Kokubun, S., and R. L. McPherron, Substorm signatures at synchronous altitude, J. Geophys. Res. 86, 11265, 1981.

Lopez, R. E., The position of the magnetotail neutral sheet in the near-Earth region, Geophys. Res. Lett. 17, 1617-1620, 1990.

Lopez, R. E. and A. T. Y. Lui, A multisatellite case study of the expansion of a substorm current wedge in the near-Earth magnetotail, J. Geophys. Res. 95, 8009-8017, 1990.

Lopez, R. E., A. T. Y. Lui, D. G. Sibeck, K. Takahashi, R. W. McEntire, L. J. Zanetti, and S. M. Krimigis, On the relationship between the energetic particle flux morphology and the change in the magnetic field magnitude during substorms, J. Geophys. Res. 94, 17105-17119, 1989.

Lopez, R. E. D. G. Sibeck, R. W. McEntire, and S. M. Krimigis, The energetic ion substorm injection boundary, J. Geophys. Res. 95, 109-117, 1990.

Lopez, R. E., A. T. Y. Lui, D. G. Sibeck, R. W. McEntire, L. J. Zanetti, T. A. Potemra, and S. M. Krimigis, The longitudinal and radial distribution of magnetic reconfigurations in the nearEarth magnetotail as observed by AMPTE/CCE, J. Geophys. Res. 93, 997-1001, 1988a.

Lopez, R. E., D. N. Baker, A. T. Y. Lui, D. G. Sibeck, R. D. Belian, R. W. McEntire, T. A. Potemra, and S. M. Krimigis, The radial and longitudinal propagation characteristics of substorm injections, Adv. Space Res. 8, (9)91-(9)95, 1988b.

Lui, A. T. Y., Estimates of currents changes in the geomagnetic tail associated with a substorm, Geophys. Res. Lett. 5, 853-856, 1978.

Lui, A. T. Y., Current disruption in the Earth's magnetosphere: observations and models, J. Geophys. Res. 101, 13067, 1996.

Maynard, N. C., W. J. Burke, E. M. Basinska, G. M. Erickson, W. J. Hughes, H. J. Singer, A. G. Yahnin, D. A. Hardy, and F. S. Mozer, Dynamics of the inner magnetosphere near times of substorm onsets, J. Geophys. Res., 101, 7705-7736, 1996.

McPherron R. L., C. T. Russell, and M. Aubry, Satellite studies of magnetospheric substorm on August 15, 1968: 9. Phenomenological model for substorms, J. Geophys. Res. 78, 3131-3149, 1973.

Nagai T., Observed magnetic substorm signatures at synchronous altitude, J. Geophys. Res. 87, 4405-4417, 1982.

Nagai T., Field-aligned currents associated with substorms in the vicinity of synchronous orbit 2. GOES2 and GOES3 observations, J. Geophys. Res. 92, 2432-2446, 1987.

Ohtani, S., K. Takahashi, L. J. Zanetti, T. A. Potemra, R. W. McEntire, and T. Iijima, Tail current disruption in the geosynchronous region, in Magnetospheric Substorms, Geophys. Monogr. Ser., 64, Eds. J. R. Kan, T. A. Potemra, S, Kokubun, and T. Iijima, pp. 131-137, AGU, Washington, D.C., 1991.

Ohtani, S., K. Takahashi, L. J. Zanetti, T. A. Potemra, R. W. McEntire, and T. Iijima, Initial signatures of magnetic field and energetic particle fluxes at tail reconfiguration: explosive growth phase, J. Geophys. Res., 97, 19311, 1992.

Rostoker, G., S.-I. Akasofu, W. Baumjohann, Y. Kamide, and R. L. McPherron, The roles of direct input of energy from the solar wind and unloading of stored magnetotail energy in driving magnetospheric substorms, Space Sci. Rev., 46, 93-111, 1987.

Sauvaud, J. A. and J. R. Winckler, Dynamics of plasma, energetic particles and fields near synchronous orbit in the nighttime sector during magnetospheric substorms, J. Geophys. Res., 85, 2043, 1980.

Slavin, J. A., D. H. Fairfield, R. P. Lepping, A. Szabo, M. J. Reiner, M. Kaiser, C. J. Owen, T. Phan, R. Lin, S. Kokubun, T. Mukai, T. Yamamoto, H. J. Singer, S. A. Romanov, J. Buechner, T. Iyemori, and G. Rostoker, WIND, GEOTAIL, and GOES9 observations of magnetic field dipolarization and bursty bulk flows in the near-tail, Geophys. Res. Lett. 24, 971974, 1997.

Tsagouri, I., H. Mavromichalaki and A. Belehaki, Azimuthal expansion of the substorm current wedge, Proc. Third International Conference on Substorms, ESA SP-389, 359-362, 1996. 